\title{
A cost accounting method of the Li-ion battery energy storage system for frequency regulation considering the effect of life degradation
}

\author{
Gangui Yan*, Dongyuan Liu, Junhui Li and Gang Mu
}

\begin{abstract}
The cost of Energy Storage System (ESS) for frequency regulation is difficult to calculate due to battery's degradation when an ESS is in grid-connected operation. To solve this problem, the influence mechanism of actual operating conditions on the life degradation of Li-ion battery energy storage is analyzed. A control strategy of Li-ion ESS participating in grid frequency regulation is constructed and a cost accounting model for frequency regulation considering the effect of battery life degradation is established. The estimated operating life and annual average cost of the Li-ion ESS under different dead bands and SOC set-points are calculated. The case studies show that the estimated operating life of the Li-ion ESS under the actual operating condition differs significantly from the nominal life provided by the manufacturer under the standard condition and the full discharge mode. This paper provides an accurate costing method for the ESS participating in grid frequency regulation to help the promotion of the ESS to participate in the ancillary service market.
\end{abstract}

Keywords: Energy storage system, Estimated operating life, Cost accounting method, Frequency regulation, Dead band

\section{Introduction}

Fossil fuel-based energy model has caused serious environmental problems whereas wind power development has gradually become an important way to push low-carbon energy transition. However, with increased large-scale wind power being centrally connected to the grid and replacing traditional frequency regulation units, power systems with high wind power penetration are facing a severe frequency regulation issue. In addition, the high randomness and variation of wind power lead to frequent action of traditional frequency regulation units resulting in increased abrasion of the mechanical devices and reduced operating life. Therefore, it is urgent to develop a new frequency regulation method for power systems.

The Li-ion ESS has flexibility and fast response characteristic, and large-scale application of Li-ion ESS has attracted extensive attention. However, current energy

\footnotetext{
* Correspondence: yangg@neepu.edu.cn

Department of Electrical Engineering, Northeast Electric Power University, Jilin, China
}

storage costs are relatively high and there is no effective frequency regulation compensation mechanism for ESSs in China. Therefore, the incentive for ESS to participate in power system frequency regulation has not been established. Consequently, some energy storage stations have not been fully utilized, resulting in a waste of resources. Accounting the cost of energy storage for frequency regulation is an important step for the development of energy-saving frequency regulation compensation strategy, which can help to promote the development of ESS to participate in the frequency regulation

Energy storage frequency regulation cost is related to not only the technology and economy of the ESS itself but also energy storage frequency regulation strategy, system frequency fluctuation characteristics etc. Previous researches have provided useful insights in these respects. The cost of ESS is closely related to its operating life which is affected by the operating conditions (charge-discharge power, depth of discharge) $[1,2]$, 
ambient temperature and other factors. The nominal life given by the manufacturers is the test result in a specific charge-discharge mode measured by the cycle chargedischarge time. When an ESS participates in grid frequency regulation, the charge-discharge mode will not be the same as the test conditions, resulting in the ESS operating life under frequency regulation mode being very different from the data given by manufacturers. Previous cost accounting method is based on the average cost of nominal life, which is very different from the actual cost. Therefore, it is an urgent need to develop a cost accounting method for frequency regulation of ESS considering the effect of life degradation.

Some domestic researchers have proposed a method that the ESS life is expressed as a sum of the available throughputs (A.h). This method introduces the grid's previous scheduling function to build a dynamic optimization model to calculate the cost and economic aspect $[3,4]$. Overseas researchers tend to convert energy storage life into a percentage to combine with the control strategy for participation in frequency regulation to calculate its economic aspect [5-7]. Real-time price of energy storage market should be considered for cost calculation. The current market price of the Li-ion ESS is $2500-4500$ (yuan / kWh), which has gone down by $60 \%$ compared to $2010[8,9]$. Taking primary frequency regulation as an example, references $[10,11]$ analyzed the model combining wind power and energy storage, and proposed an ESS's control strategy to reduce wind curtailment and to participate in primary frequency regulation. With the maximum profit of wind-storage combination as the objective, an optimization model of ESS was established. For secondary frequency regulation, references [12-14] drew a conclusion that the annual investment cost of one ESS is 2.7-4.7 times as a heatengine plant. However, the ESS is superior in the operation and maintenance costs. Existing researches have focused on the optimization of control strategies and the economic benefits, while the degradation of life was only considered under a given control strategy and given frequency regulation modes [15-18]. Therefore, current studies are short of a comprehensive and effective cost accounting method, which does not encourage the formation of ancillary service compensation mechanism, restrict the development of the ESS, and even hamper the grid integration of large-scale wind power.

This paper focuses on the cost accounting of the ESS to participate in power system frequency regulation. In Section 2, Li-ion battery life degradation model is constructed. Section 3 shows the influence mechanism of actual operating conditions on energy storage life degradation. A frequency regulation control strategy and an ESS frequency regulation cost accounting model considering life degradation are established in Section 4. The estimated operating life and the annual cost of the ESS under different frequency dead bands and SOC setpoints are analyzed in Section 5, whereas Section 6 draws the conclusions.

\section{Methods}

\subsection{Li-ion battery life degradation model}

Under given charge-discharge mode and ambient temperature, the Li-ion battery cycle life refers to the cycle charge-discharge time until the battery capacity retention rate drops down to the specified nominal capacity value.

The Li-ion energy storage life degradation refers to life loss caused by the deterioration of battery functional properties and changes of working conditions. The life degradation is closely related to battery cycle time, charge-discharge status, temperature and other factors. It is expressed as a percentage reduction of Li-ion battery cycle life, and includes static degradation and dynamic degradation as:

$$
X=X_{S}+X_{D}
$$

The static degradation $X_{S}$ is caused by the degradation of functional properties of the Li-ion battery, including the thickening of the electrolyte interface film, the oxidation of electrolyte and the loss of electrode active material. Such functional property degradation will increase the internal resistance of the storage battery and lead to capacity reduction. Since $X_{S}$ is independent of the operating condition, it is generally considered to be linear with shelf life of the battery. The yearly static degradation can be expressed as:

$$
X_{S}=\frac{100 \%}{T}
$$

where $T$ represents the battery shelf life/year. For example, if the Li-ion battery shelf life is 20 years, one year's static degradation is $1 / 20=5 \%$.

The dynamic degradation $X_{D}$ corresponds to the degradation caused by changes in the operating status of the Li-ion battery. Operating conditions include the depth of discharge and the charge-discharge rate, corresponding to the battery's charge-discharge process. As actual charge-discharge cycles are aperiodic, the dynamic life degradation is non-linear. Therefore, actual operating conditions should be considered to calculate the dynamic degradation given by:

$$
X_{D}=\sum_{k=1}^{\mathrm{n}} 1 / C_{k(i j)}
$$

where $k$ refers to the $k$ th charge-discharge interval, $i$ and $j$ represent the start and end of charge-discharge with the SOC values being $\mathrm{SOC}_{\mathrm{i}}$ and $\mathrm{SOC}_{\mathrm{j}}$, respectively. $n$ is the number of charge-discharge cycles in the sampling 
time. $C_{k}(i j)$ is the number of cycles when the $\mathrm{Li}$-ion ESS's SOC charges and discharges between $i$ and $j$ until the actual capacity of the storage battery drops down to $60 \%$ of its nominal capacity, and is given by:

$$
\frac{1}{C_{k(i j)}}=\frac{1}{2}\left(\frac{1}{C_{k(i)}}-\frac{1}{C_{k(j)}}\right)
$$

where, as regards to the $k$ th interval, $C_{k(i)}$ and $C_{k(j)}$ are the cycle numbers when the SOC charges and discharges from $S O C_{i}$ and $S O C_{j}$ to $100 \%$, respectively, until the actual capacity of the storage battery drops down to $60 \%$ of its nominal capacity. $1 / C_{k(i)}$ and $1 / C_{k(j)}$ are the dynamic cycle degradation that the SOC charges and discharges between $S O C_{i}$ and $S O C_{100 \%}$, and $S O C_{j}$ and $S O C_{100 \%}$, respectively. The derivation of (4) can be explained by considering the dynamic degradation $\left(1 / C_{k(i j)}\right)$ to be the dynamic degradation of SOC from $S O C_{i}$ to $S O C_{j}$ which equals half the value of the cycle dynamic degradation between $\mathrm{SOC}_{i}$ and $S O C_{100 \%}$ minus that between $S O C_{j}$ and $S O C_{100 \%}$.

Since the Li-ion battery life is measured by the number of cycles, the static degradation and the dynamic degradation need to be equivalent to the reduction of the number of cycles. Assuming the lithium battery cycle life is 4500 times under a given condition (80\% DOD), and at this time, the capacity retention rate drop to $60 \%$. Similarly, if the Li-ion battery idles for 20 years, the capacity retention rate will also drop to $60 \%$. As the static degradation is linear, it can be considered that it will consume $4500 \times 5 \%=225$ cycle times if the Li-ion battery remains idle for one year. So the percentage of life degradation caused by the static degradation and dynamic degradation can be considered in a similar process causing the Li-ion battery capacity retention rate to drop to $60 \%$.

In summary, the Li-ion battery life degradation mode under actual operating conditions is given by:

$$
X=X_{S}+X_{\mathrm{D}}=\frac{100 \%}{T}+\sum_{k=1}^{n}\left|\frac{1}{2 C_{k(i)}}-\frac{1}{2 C_{k(j)}}\right|
$$

Therefore, it is only necessary to analyze the relationship between the cycles of Li-ion ESS and the state of charge (SOC) or the depth of discharge (DOD). Thus, the Li-ion ESS life degradation of any charge-discharge interval under actual operating conditions can be calculated and the operating life of energy storage battery can be estimated.

\subsection{Influence of depth of discharge on Li-ion ESS operat- ing life}

Li-ion batteries are tested at normal room temperature $\left(20 \pm 5{ }^{\circ} \mathrm{C}\right)$, and are charged and discharged with constant current and constant voltage (1C model). Using different depth of discharge as each charge-discharge indicator, Li-ion battery cycle life refers to the number of cycles until the actual capacity of the battery drops down to $60 \%$ nominal capacity.

The measured data of the LiFePO4 battery (one kind of Li-ion battery) shown in Fig. 1 is given by manufacturers. Under standard conditions, with different DOD as each charge-discharge indicator, it shows the variations of the LiFePO4 battery actual capacity retention rate as the number of cycles changes.

It can be seen from Fig. 1 that the relationship between battery capacity retention rate and the number of cycles is analogously parabolic. The deterioration rate of the battery is reflected in two stages. In the first stage, the battery decay rate gradually decreases, indicating that the battery tends to self-stabilize its state. In the second stage, the battery decay rate increases, indicating that the battery begins to accelerate its aging. It can also be seen from Fig. 1 that the higher the DOD value is, the faster aging rate of the battery becomes, and the fewer the cycle is. The relationship between the discharge depth and the cycle life is approximately exponential [3] and for the LiFePO4 battery it can be fitted as:

$$
C_{i}=28270 e^{\left(-2.401 D O D_{i}\right)}+2.214 e^{\left(5.901 D O D_{i}\right)}
$$

where $C_{i}$ is the number of cycles when the depth of discharge is $D O D_{i}$.

Fig. 2 shows the relationship between DOD and cycle life calculated using (6). For other kinds of batteries similar fitting methods can also be used.

The formula $D O D_{i}=1-S O C_{i}$ means that battery charges and discharges repeatedly between $S O C_{i}$ and $S O C_{100 \%}$ at $D O D_{i}$. According to $D O D_{i}=1-S O C_{i}$ and (6), the relationship between the cycle life and SOC can be expressed as:

$$
C_{i}=28270 e^{\left(-2.401\left(1-S O C_{i}\right)\right)}+2.214 e^{\left(5.901\left(-S O C_{i}\right)\right)}
$$

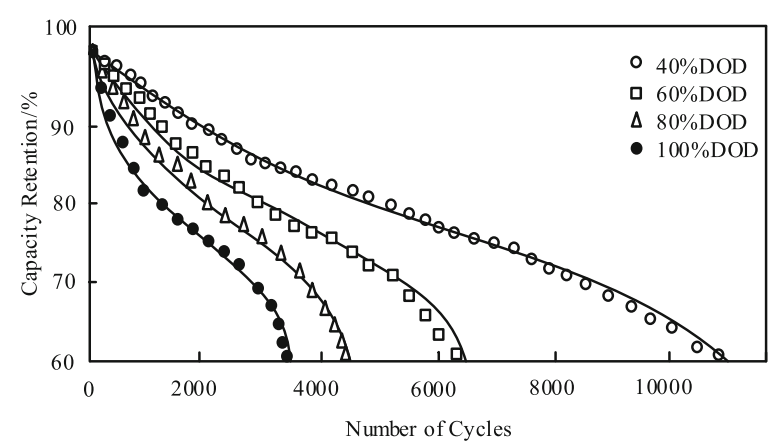

Fig. 1 Battery capacity retention under different DOD 


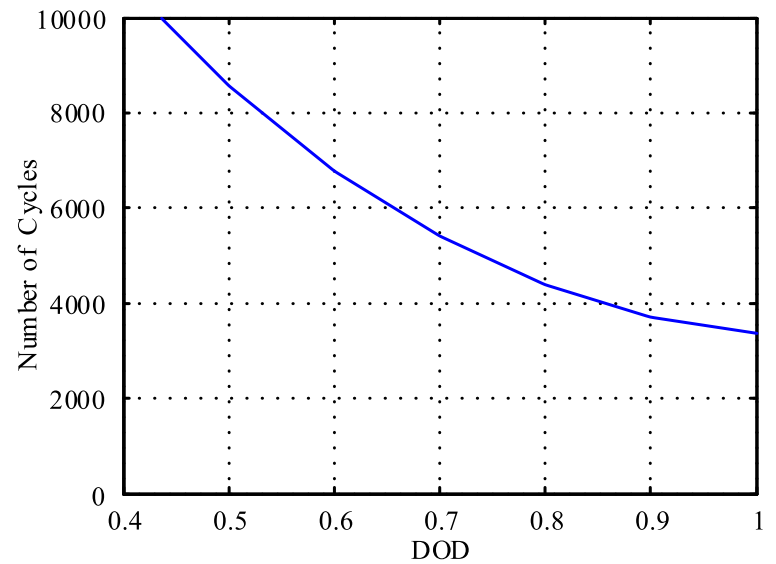

Fig. 2 The relationship between DOD and cycle life

In summary, combing with the depth of discharge and state of charge, the annual life degradation model of energy storage battery under actual operating conditions is given as:

$$
\begin{aligned}
& X=\frac{100 \%}{T}+ \\
& \sum_{k=1 n} \mid \begin{array}{l}
\frac{1}{2 \times\left[28270 e^{-2.401\left(1-S O C_{k(i)}\right)}+2.214 e^{5.901\left(1-S O C_{k(i)}\right)}\right]} \\
-\frac{1}{2 \times\left[28270 e^{-2.401\left(1-S O C_{k(j)}\right)}+2.214 e^{5.901\left(1-S O C_{k(j)}\right)}\right]}
\end{array}
\end{aligned}
$$

\subsection{The cost accounting model for the frequency regulation of the Li-ion ESS considering the effect of life degradation}

\subsubsection{The cost accounting model}

The cost accounting model of the Li-ion ESS is determined by the total initial investment cost, estimated operating life, operation and maintenance costs, and is give as:

$$
C_{A}=C_{I N V} / T_{\mathrm{LC}}+\mathrm{C}_{\mathrm{OM}}
$$

where $C_{A}$ is the annual cost of the Li-ion ESS, $C_{I N V}$ is the total cost of the initial investment of the Li-ion ESS, $T_{L C}$ is the estimated operating life (in years) of the Li-ion ESS considering the life degradation. $\mathrm{C}_{\mathrm{O} \& \mathrm{M}}$ is the annual operation and maintenance cost. Because the Li-ion ESS $\mathrm{C}_{\mathrm{O \& M}}$ is much less than the initial investment, it is considered to be fixed in the case setting. The total cost of the initial investment of the Li-ion ESS is given by

$$
C_{I N V}=\lambda_{\mathrm{P}} P_{E S S}+\lambda_{\mathrm{E}} E_{E S S}
$$

where $P_{E S S}$ and $E_{E S S}$ are the respective rated power and capacity of the Li-ion ESS, $\lambda_{P}$ is the unit price of the Liion ESS power, and $\lambda_{\mathrm{E}}$ is the unit price of the Li-ion ESS capacity. These parameters are given in Table 1 of the case setting.

\subsubsection{The control strategy of the Li-ion ESS participating in power grid frequency regulation}

(1) Energy storage power output constraints

$$
P_{t}^{\min } \leq P_{t} \leq P_{t}^{\max }
$$

where $P_{t}$ is the charge-discharge power of the Li-ion ESS. The ESS works in the charge state when $P_{t}>0$, and in the discharge state when $P_{t}<0$.

\section{(2) Storage SOC constraints}

$$
\begin{aligned}
& S O C(t+\Delta t)=S O C(t)+\frac{w_{f r} \eta}{E_{E S S}} \\
& S O C^{\min } \leq S O C(t+\Delta t) \leq S O C^{\max }
\end{aligned}
$$

where $w_{f r}$ is the energy of the Li-ion ESS participating in the grid frequency regulation, is the efficiency of the Li-ion ESS. Because manufacturers usually only provide the total efficiency ( ) of ESSs, it is considered as the balanced result of charge and discharge efficiency in this paper. SOC ${ }^{\min }$ and $\mathrm{SOC}^{\max }$ are the minimum and maximum values of allowed ESS's SOC.

The ESS utilizes the bi-directional flow of the battery energy to support network frequency to prevent it from deviating the standard range. The ESS charging and discharging power is given as [2]:

$$
\left\{\begin{array}{l}
p t=K_{E S S} \times\left(f_{t}-f_{\text {ref } 1}\right) f_{t}>f_{\text {ref } 1} \\
p t=0 \quad f_{\text {ref } 2}<f_{t}<f_{\text {ref } 1} \\
p t=K_{E S S} \times\left(f_{t}-f_{\text {ref } 2}\right) \quad f_{t}<f_{\text {ref } 2}
\end{array}\right.
$$

Table 1 The LiFePO4 battery ESS System installed capacity and the power/capacity parameters

\begin{tabular}{ll}
\hline Parameter & Number \\
\hline $\mathrm{P}_{N W F} / \mathrm{MW}$ & 54.4 \\
$\mathrm{P}_{E S S} / \mathrm{MW}$ & 5 \\
$\mathrm{E}_{E S S} / \mathrm{MWh}$ & 2.5 \\
$\lambda_{P} /$ (yuan.kW-1) & 1000 \\
$\lambda_{E} /$ (yuan.kWh-1) & 1880 \\
CO\&M/(yuan $\cdot k W-1)$ & 24 \\
SOC $_{\text {set-point }}$ & 0.5 \\
SOC $^{\text {min }}$ & 0.1 \\
SOC $^{\text {max }}$ & 1 \\
\hline
\end{tabular}


When the power supply is higher than the load demand, the system frequency rises above $f_{\text {refl }}$. The ESS charges and absorbs power from the power grid until the system frequency drops down to $f_{\text {refl. }}$. When the power supply is less than the load demand and the system frequency drops below $f_{\text {ref2 }}$, the ESS discharges and releases power to the power grid until the system frequency moves up to $f_{\text {ref2 } 2}$. The ESS's unit adjustment power $K_{E S S}$ is directly related to the effect of the control strategy. Because of the limitation of energy storage capacity, this control strategy is only suitable for the primary frequency regulation of an interconnected system.

It can be seen from (14) that the frequency regulation dead band $\left(f_{r e f 1}, f_{r e f 2}\right)$ directly affects the chargedischarge power $\left(p_{t}\right)$ of the ESS, and its life degradation and operating life $T_{L C}$.

\subsubsection{The calculation of the ESS frequency regulation power} The main benefit of the Li-ion ESS for frequency regulation is from frequency regulation energy $w_{f r}$. As for the frequency regulation period from $t_{i}$ to $t_{j}$, the frequency regulation energy $w_{f r}$ is given as:

$$
w_{f r}=\int_{t_{i}}^{t_{j}} p_{t} d t=\sum_{t=t_{i}}^{t_{j}} p_{t} \times \Delta t
$$

where $p_{t}$ is the charge-discharge power of the Li-ion ESS in the period from $t_{i}$ to $t_{j}$.

\subsubsection{Calculation of the ESS estimated operating life $T_{L C}$}

As for the energy storage frequency regulation period $t_{i}$ to $t_{j}$, the change of the ESS SOC is:

$$
\operatorname{SOC}\left(t_{j}\right)=\operatorname{SOC}\left(t_{i}\right)+\frac{w_{f r} \eta}{E_{E S S}}
$$

According to $S O C\left(t_{j}\right)$ and $S O C\left(t_{i}\right)$, and combining (4) and (7), the dynamic degradation $X_{D}$ can be obtained. As previously described, the static degradation $X_{S}$ of the period is calculated according to (2). In summary, the life degradation of the frequency regulation period $\left(t_{i}, t_{j}\right)$ is calculated as (17).

$$
\begin{aligned}
& x\left(t_{i}, t_{j}\right)=X_{S}+X_{D}=\frac{t_{j}-t_{i}}{T \times 365 \times 24 \times 60}{ }^{*} 100 \%+ \\
& \mid \frac{1}{2 \times\left[28270 e^{-2.401\left(1-S O C\left(t_{i}\right)\right)}+2.214 e^{5.901\left(1-S O C\left(t_{i}\right)\right)}\right]} \\
& -\frac{1}{2 \times\left[28270 e^{-2.401\left(1-S O C\left(t_{j}\right)\right)}+2.214 e^{\left.5.901\left(1-S O C\left(t_{j}\right)\right)\right]}\right.} \mid
\end{aligned}
$$

Similarly, according to the given frequency curve and dead band, $\triangle \mathrm{SOC}$ changes within one year can be calculated. Combining with the life degradation model of the energy battery in (8), one-year life degradation $\left(X_{y}\right)$ of the Li-ion ESS is expressed as:

$$
\begin{gathered}
X_{y}=X_{S(y)}+X_{D(y)}=\frac{100 \%}{T}+ \\
\sum_{k=1}^{n} \mid \begin{array}{l}
\frac{1}{2 \times\left[28270 e^{-2.401\left(1-S O C_{k(i)}\right)}+2.214 e^{5.901\left(1-S O C_{k(i)}\right)}\right]} \\
-\frac{1}{2 \times\left[28270 e^{-2.401\left(1-S O C_{k(j)}\right)}+2.214 e^{5.901\left(1-S O C_{k(j)}\right)}\right]} \mid
\end{array}
\end{gathered}
$$

where $\mathrm{n}$ is the number of charge-discharge cycles in one year. Fig. 3 shows the calculation flowchart to obtain $X y$.

It can be assumed that the annual demand for frequency regulation in late years is similar to the demand of the first year. The actual capacity of the Li-ion ESS at the end of the first year is the rated capacity of the Li-ion ESS at the second year. So the Li-ion ESS life degradation of the second year can be calculated and so on for the rest years. When the Li-ion ESS operation life degradation process reaches $100 \%$ as shown in (19), the estimated operating life $\left(T_{L C}\right)$ under the corresponding dead band can be obtained.

$$
\sum_{y=1}^{y=T_{L C}} X_{y}=100 \%
$$

According to different estimated operating life $T_{L C}$ of the Li-ion ESS under different dead bands, the average cost $C_{A}$ can be calculated according to (9) and (10).

\section{Results and discussion}

\subsection{Case analysis}

\subsubsection{Case setting}

The selected case is a wind farm with an ESS in Liaoning power grid, which is an interconnected system. In 2015, the installed capacity of the Liaoning power grid was $4.32 \times 10^{4} \mathrm{MW}$, and the maximum load was $2.34 \times$ $10^{4} \mathrm{MW}$. The wind farm is rated at 54.4 MW $\left(P_{N W F}\right)$ and equipped with 64 G58-850 kW doubly-fed asynchronous wind generators, whereas the rated power of the ESS is $5 \mathrm{MW}$. In order to achieve similar effect as synchronous generator frequency regulation, the frequency coefficient of the Li-ion ESS is set the same as the synchronous generators, i.e. $K_{E S S}=0.4 \times P_{N W F}=$ $21.76 \mathrm{MW} / \mathrm{Hz}$. According to the power system frequency regulation need (including the primary frequency regulation and the secondary frequency regulation), the regulation time is about $30 \mathrm{~min}$. Thus, the storage system capacity $E_{E S S}$ is set as $5 \mathrm{MW} \times 0.5 \mathrm{~h}=2.5 \mathrm{MWh}$. In the case study, the ESS is only used for frequency regulation. The LiFePO4 battery energy storage system is chosen as it has the best prospect of the current market application. The unit ESS price is shown in Table 1, the sampling period of the wind farm frequency is $1 \mathrm{~min}$ and the data amount is 525,600. 


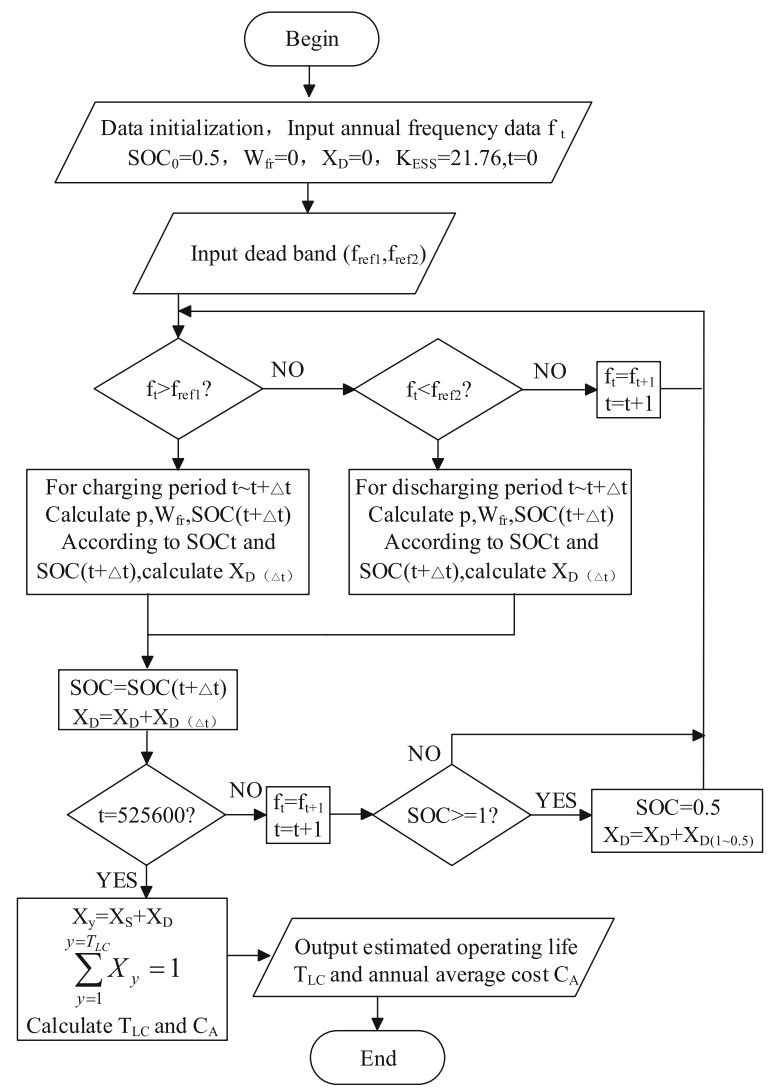

Fig. 3 The calculation flowchart of Li-ion ESS estimated operating life and annual average cost

\subsubsection{Calculation results and analysis}

In this study, the frequency of the wind farm is used as the frequency regulation target, and $f_{\text {ref }(1,2)}=50 \pm x \mathrm{~Hz}$ is selected as the frequency regulation dead band. When the system frequency offset exceeds the rated frequency by $\pm x \mathrm{~Hz}$, the ESS will participate in system frequency regulation.

\subsubsection{Frequency regulation cost accounting under the given dead band}

(1) The sharing cost accounting without considering the impact of life degradation

When the impact of ESS life degradation is not taken into account, traditional storage cost accounting is just a sharing accounting method, which uses the nominal life provided by the manufacturers. The initial investment of the Li-ion ESS is $970 \times 10^{4}$ yuan, and the Li-ion ESS nominal life is 15 years from manufacturers. The average life degradation is $6.67 \%$. The annual sharing cost equals $76.7 \times 10^{4}$ yuan (including the cost of operation and maintenance). If the given discharge depth is $80 \%$ DOD, the nominal life of the energy storage battery is 4500 times and the annual sharing number is 300 times, equivalent to the ESS being fully charged approximately once a day.

(2) The annual average cost accounting considering the impact of energy storage life degradation under the given frequency regulation dead band.

The given frequency regulation dead band is $50 \pm$ $0.04 \mathrm{~Hz}$ and when the system frequency offset exceeds the rated frequency by $\pm 0.04 \mathrm{~Hz}$, the ESS will participate in the system frequency regulation. Fig. 4 shows the calculated variations of the Li-ion ESS charge-discharge power and the SOC in a typical day. As seen, the Li-ion ESS is charged fully twice a day. One day's frequency regulation power and life degradation are 3.297MWh and $0.0359 \%$, respectively. According to the actual annual frequency curve of the wind farm, this model can be applied to calculate the annual life degradation of the $\mathrm{Li}$-ion ESS, and the result is $11.59 \%$. The annual frequency regulation power is $1175.9 \mathrm{MWh}$. This indicates that the ESS is fully charged 432 times within one year, and the estimated operating life is 8.6 years, representing a significant reduction from the nominal life of 15 years. The annual average cost is thus $124.4 \times 10^{4}$ yuan, higher than $76.7 \times 10^{4}$ yuan from the traditional sharing accounting.

\subsubsection{The annual average cost accounting under different frequency regulation dead bands}

Using different frequency regulation dead bands, the estimated operating life and annual average cost of the Liion ESS are compared in Table 2.

As can be seen from Table 2, if the frequency regulation dead band is $\pm 0.06 \mathrm{~Hz}$, the annual average cost is

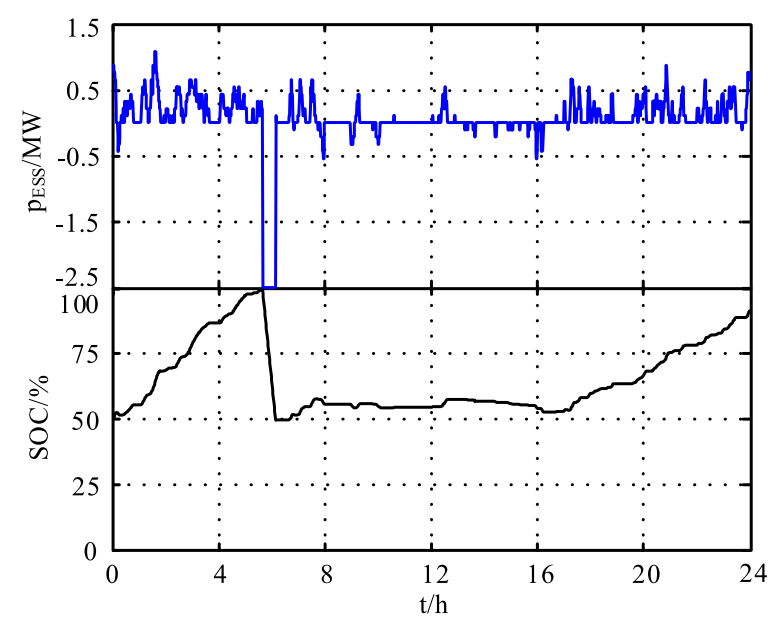

Fig. 4 Variations of the Li-ion ESS charge-discharge power and the $\mathrm{SOC}$ in a typical day (frequency regulation dead band is $50 \pm 0.04 \mathrm{~Hz})$ 
Table 2 Estimated operating life and annual average cost of the Li-ion ESS under different frequency regulation dead bands

\begin{tabular}{llllll}
\hline $\begin{array}{l}\text { frequency regulation dead } \\
\text { bands } / \mathrm{Hz}\end{array}$ & \pm 0.033 & \pm 0.04 & \pm 0.05 & \pm 0.06 & $\begin{array}{l}\text { nominal } \\
\text { life(15y) }\end{array}$ \\
\hline$W_{f /} / 10^{4} \mathrm{kWh}$ & 189.62 & 117.59 & 54.34 & 21.14 & - \\
Annual life degradation/\% & 16.81 & 11.59 & 8.21 & 6.23 & 6.67 \\
$T_{L C}$ year & 5.95 & 8.63 & 12.18 & 16.05 & 15 \\
$C_{A} / 10^{4}$ yuan & 175.0 & 124.4 & 91.6 & 72.4 & 76.7 \\
Fully charging cycle & 696 & 432 & 201 & 78 & - \\
\hline
\end{tabular}

$72.4 \times 10^{4}$ yuan, which is close to the $76.7 \times 10^{4}$ yuan according to the nominal 15 -year life provided by manufacturers. When the frequency regulation dead band is $\pm 0.033 \mathrm{~Hz}$, the estimated operating life of the energy storage is reduced to 5.95 years and its annual average cost is increased to $175 \times 10^{4}$ yuan. It can be concluded that smaller frequency regulation dead band results in more frequent Li-ion ESS operation, leading to shorter battery operating life and higher average annual cost.

The above example was analyzed when the SOC setpoint is $50 \%$. Analyzing data reveals that the SOC is usually in the range of 30 to $100 \%$ when the energy storage participates in frequency regulation. Therefore, it is necessary to analyze whether SOC set-point of $50 \%$ is the optimal condition.

Fig. 5 shows the statistics histogram of the occurrence of different system frequency whereas Fig. 6 illustrates the annual duration of the energy storage frequency regulation power for different frequency dead bands. From Figs. 5 and 6, it can be seen that over-frequency occurs $70.19 \%$ in one year and the duration of charge is longer than that of discharge. Therefore, the choice of SOC set-point is very important and affects the number of energy storage fully charging times and life degradation.

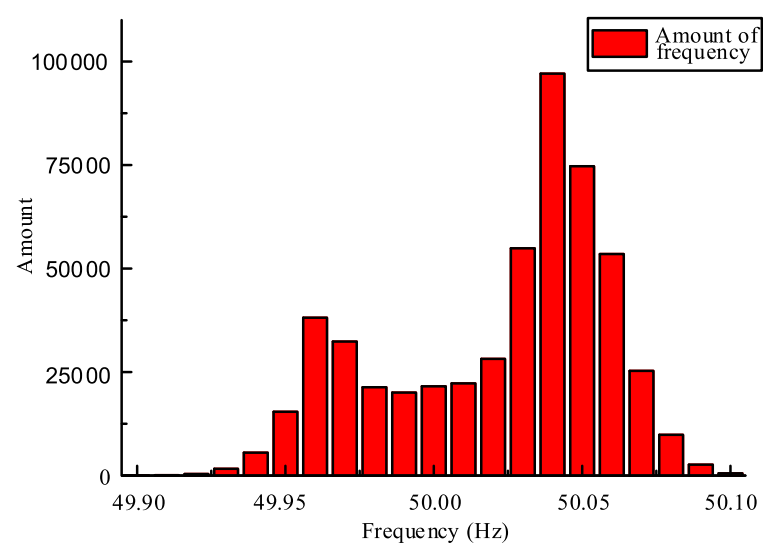

Fig. 5 The statistics histogram of frequency amount

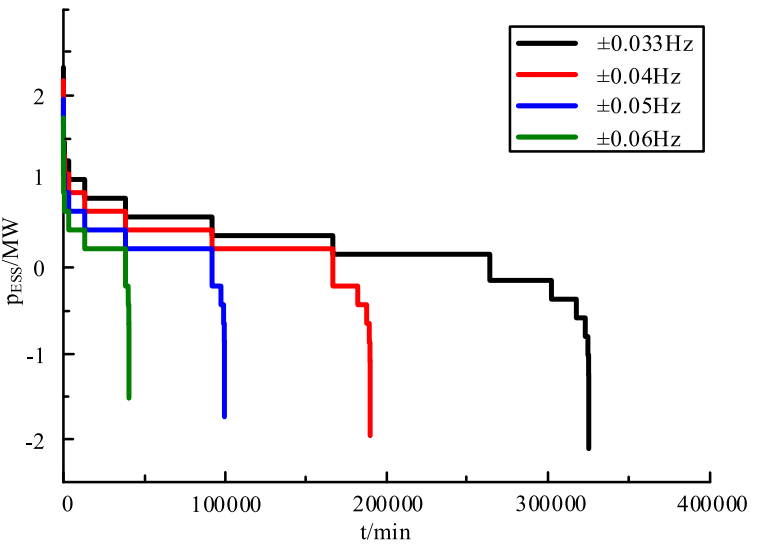

Fig. 6 Annual energy storage frequency regulation power duration curve

\subsubsection{The annual average cost accounting under different SOC set-points and different frequency regulation dead bands}

If the SOC set-point is reduced, the number of the ESS's fully charging times can be reduced. However, the deep charge-discharge mode will increase the life degradation of the Li-ion ESS. Fig. 7 and Fig. 8 show the life degradation and estimated operating life of the energy storage under different SOC set-points and frequency regulation dead bands. It is shown that under the same frequency regulation dead band, the smaller the SOC set-point is, the higher the annual life degradation and the shorter of estimated operating life of the energy storage are. For example, when the SOC set-point is 20\% (deep chargedischarge state) and the frequency regulation dead band is $\pm 0.033 \mathrm{~Hz}$, the estimated operating life of the storage is the shortest, only 4.3 years, and the annual average cost is the largest at $237.6 \times 10^{4}$ yuan. This compares to 16.05 years and $72.4 \times 10^{4}$ yuan with the SOC set-point

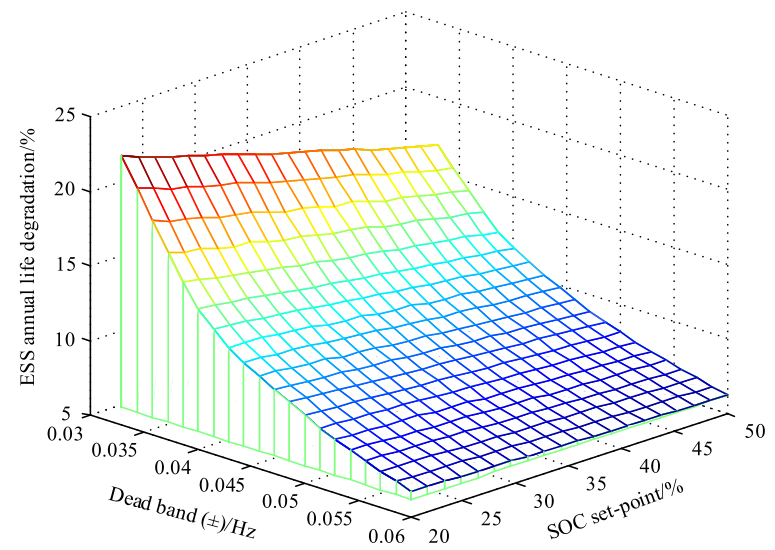

Fig. 7 The life degradation of the ESS under different SOC set-points and different frequency regulation dead bands 


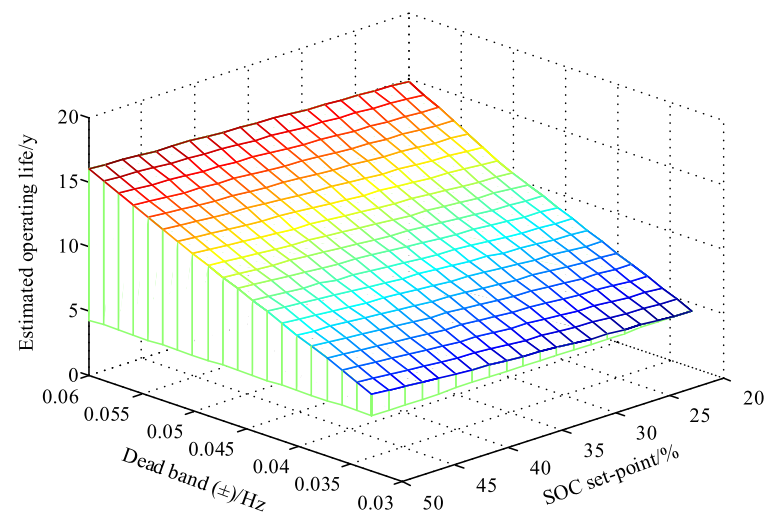

Fig. 8 The estimated operating life of the ESS under different SOC set-points and different frequency regulation dead bands

of $50 \%$ and the frequency regulation dead band of $\pm 0.06 \mathrm{~Hz}$ as previously discussed.

As small SOC set-point leads to high frequency regulation power and thus, it is necessary to assess the life degradation caused by the unit frequency regulation power to determine the optimal SOC set-point. Fig. 9 shows the life degradation of unit frequency regulation power under different SOC set-points and different frequency regulation dead bands. It shows that when the frequency regulation dead band is $\pm 0.033 \mathrm{~Hz}$ and the SOC set-point is $50 \%$, the ESS life degradation of the unit frequency regulation power is the smallest. The estimated operating life of the Li-ion ESS is 5.95 years and the annual average cost is $175 \times 10^{4}$ yuan. In this case, it will consume relatively little life to complete more frequency regulation tasks.

\section{Conclusions}

In order to improve the accuracy of the cost accounting method for frequency regulation of the Li-ion battery energy storage system, a model of Li-ion battery life

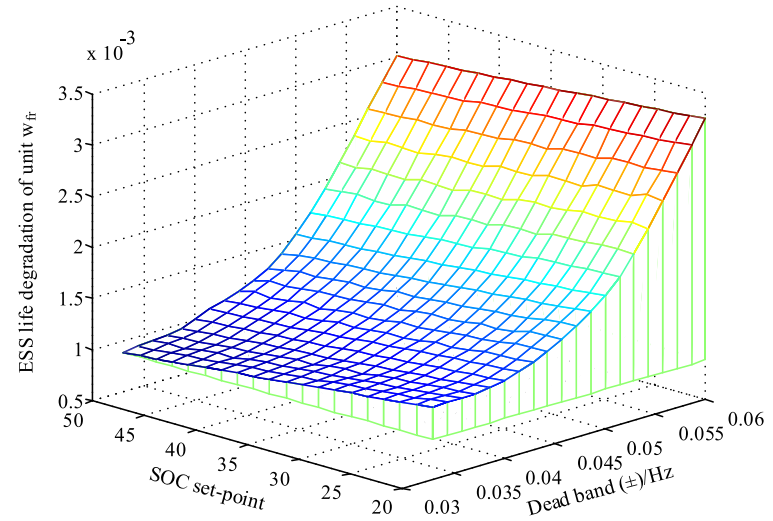

Fig. 9 The Li-ion ESS life degradation of unit frequency regulation power under different SOC set-points and different frequency regulation dead bands degradation is developed in this paper. The influence of DOD on the Li-ion ESS operating life is analyzed and the ESS life degradation in any frequency regulation period under actual operating conditions are obtained. Finally, an effective frequency regulation cost accounting method is proposed to calculate the annual average cost and the estimated operating life of the Li-ion ESS under different frequency regulation dead bands and SOC setpoints, which are significantly different from the sharing cost calculated by traditional method and the nominal life. The proposed method provides an accurate annual average cost of the ESS and is thus of great significance to accelerate the construction of the pricing mechanism of the frequency regulation ancillary service.

\section{Acknowledgements}

This work is supported in part by Industrial Innovation of Jilin Province Development and Reform Commission (2017C017-2), Science \& Technology Project of SGCC (Key technology and application of super large capac-ity battery energy storage system),and Jilin Provincial "13th Five-Year Plan" Science and Technology Project ([2016] 88).

\section{Authors' contributions}

GG. Y contributed to design and analysis of the study and drafted the manuscript; DY. L carried out the studies about the influence mechanism of actual operating conditions on the Li-ion battery energy storage life degradation; JH. L worked on the cost accounting model for frequency regulation of Li-ion battery energy storage system considering the effect of life degradation; MG contributed to the revision of the manuscript. All authors have read and approved the final manuscript.

\section{Competing interests}

The authors declare that they have no competing interests.

Received: 31 May 2017 Accepted: 9 January 2018

Published online: 05 February 2018

\section{References}

1. Ying, W. A. N. G., Zhi, Z. H. O. U., Audun, B. O. T. T. E. R. U. D., et al. (2016). Stochastic coordinated operation of wind and battery energy storage system considering battery degradation. Journal of Modern Power Systems and Clean Energy, 4(4), 1-12.

2. Yan, G., Zhu, X., Junhui, L. I., et al. (2013). Control strategy design for hybrid energy storage system with intrinsic operation life measurement and calculation. Dianli Xitong Zi donghua/ automation of Electric Power Systems, 37(1), 110-114.

3. Yang, Y., Wei, P., Wei, D., et al. (2015). Day-Ahead Scheduling Optimization for Microgrid with Battery Life Model[J]. Transactions of China Electrotechnical Society, 30(22), 172-180.

4. Xiao H, Pei W, Yang Y, et al. 2015, Energy storage capacity optimization for microgrid considering battery life and economic operation. High Voltage Engineering. 41(10), 3256-3265.

5. Lian, B., Sims, A., Yu, D., et al. (2016). Optimizing LiFePO4 battery energy storage Systems for Frequency Response in the UK system. IEEE Transactions on Sustainable Energy, 6(1), 253-262.

6. Serban, I., \& Marinescu, C. (2014). Control strategy of three-phase battery energy storage Systems for Frequency Support in microgrids and with uninterrupted supply of local loads. IEEE Trans Power Electron, 29(9), 50105020.

7. Xiang, Y., Wei, Z., Sun, G., et al. (2015). Life cycle cost based optimal configuration of battery energy storage system in distribution network. Power System Technology, 39(1), 264-270.

8. RL, F. A. R. E. S., MEYERS, J. P., \& WEBBER, M. E. (2014). A dynamic modelbased estimate of the value of a vanadium redox flow battery for frequency regulation in Texas. App/ Energy, 113, 189-198.

9. Sutopo, W., Atikah, N., Purwanto, A., et al. (2015). A cost estimation model to assess the feasibility of Li-ion battery development based on targeted cost 
by market approach// international conference on electrical engineering and computer science. IEEE, 376-380.

10. SWIERCZYNSKI, M., STROE, D. I., STAN, A. I., et al. (2014). Selection and performance degradation modeling of Li MO2/Li4Ti5O12 and Li Fe PO4/C battery cells as suitable energy storage systems for grid integration with wind power plants: An example for the primary frequency service. IEEE Transactions on Sustainable Energy, 5(1), 90-100.

11. Tao, Y., Zhanzhan, Q. U., Dong, H., et al. (2014). Economic analysis of the virtual power plants with large-scale battery energy storage systems. Dianli Xitong Zidonghua/automation of Electric Power Systems, 38(17), 98-104.

12. Dayu, C. H. E. N., Lizi, Z. H. A. N. G., Shu, W. A. N. G., et al. (2013). Development of energy storage in frequency regulation market of United States and its enlightenment. Automation of Electric Power Systems, 37(1), 9-13.

13. Kazempour, S. J., Moghaddam, M. P., Haghifam, M. R., et al. (2009). Electric energy storage systems in a market-based economy: Comparison of emerging and traditional technologies. Renew Energy, 34(12), 2630-2639.

14. Cui, H. Y. (2014). The development of circular economy of thermal power in western Jilin. Adv Mater Res, 962-965, 2323-2326.

15. Aghamohammadi, M. R., \& Abdolahinia, H. (2014). A new approach for optimal sizing of battery energy storage system for primary frequency control of islanded microgrid. Int J Electr Power Energy Syst, 54(1), 325-333.

16. Świerczyński, M., Stroe, D. I., Stan, A. I., et al. (2013). Primary frequency regulation with Li-ion battery energy storage system: A case study for Denmark// ecce Asia Downunder. IEEE, 487-492.

17. Thorbergsson, E., Knap, V., Swierczynski, M., et al. (2013). Primary frequency regulation with Li-ion battery based energy storage system - evaluation and comparison of different control strategies// telecommunications energy conference 'smart power and efficiency. VDE, 1-6.

18. Malysz, P., Sirouspour, S., \& Emadi, A. (2014). An optimal energy storage control strategy for grid-connected microgrids. IEEE Transactions on Smart Grid, 5(4), 1785-1796.

\section{Submit your manuscript to a SpringerOpen ${ }^{\circ}$ journal and benefit from:}

- Convenient online submission

Rigorous peer review

- Open access: articles freely available online

- High visibility within the field

- Retaining the copyright to your article

Submit your next manuscript at $\gg$ springeropen.com 